\title{
SVC Dynamic Analytical Model
}

\author{
D.Jovcic, Member, IEEE, N.Pahalawaththa, Member IEEE, M.Zavahir, Member IEEE, H.Hassan
}

\begin{abstract}
This paper presents a linear state-space model of a Static VAR Compensator. The model consists of three individual subsystem models: an AC system, a SVC model and a controller model, linked together through $d-q$ transformation. The issue of non-linear susceptance-voltage term and coupling with a static frame of reference is resolved using an artificial rotating susceptance and linearising its dependence on firing angle. The model is implemented in MATLAB and verified against PSCAD/EMTDC in the time and frequency domains. The verification demonstrates very good system gain accuracy in a wide frequency range $f<150 H z$, whereas the phase angle shows somewhat inferior matching above $25 \mathrm{~Hz}$. It is concluded that the model is sufficiently accurate for many control design applications and practical stability issues. The model's use is demonstrated by analyzing the dynamic influence of the PLL gains, where the eigenvalue movement shows that reductions in gains deteriorate system stability.
\end{abstract}

Index Terms-Modeling, Power system dynamic stability, State space methods, Static VAR Compensators, Thyristor converters.

\section{INTRODUCTION}

tatic VAR Compensators are mostly analyzed using EMTP type programs like PSCAD/EMTDC or RTDS. These simulation tools are accurate but they employ trial and error type studies only, implying a tedious blind search for the best solution in the case of complex analysis/design tasks. In order to apply dynamic systems analysis techniques or modern control design theories that would in the end shorten the design time, optimize resources and offer new configurations, there is a need for a suitable and accurate system dynamic model. In particular, an eigenvalue and frequency domain analysis based on an accurate state space system model would prove invaluable for system designers and operators.

There have been a number of attempts to derive an accurate analytical model of a Static VAR Compensator (SVC), or a Thyristor Controlled Series Capacitor (TCSC), that can be employed in system stability studies and controller design [1][7].

The SVC model presented in [1] belongs to classical power system modeling based on the fundamental frequency repre-

This work is supported by The Engineering and Physical Sciences Research Council (EPSRC) UK, grant no GR/R11377/01.

D. Jovcic and H.Hassan are with Electrical and Mechanical Engineering, University of Ulster, Newtownabbey, BT370QB, United Kingdom, (e-mail: d.jovcic@ulst.ac.uk, ha.hassan@ulster.ac.uk).

N.Pahalawaththa and M,Zavahir are with Transpower NZ Ltd, Po Box 1021, Wellington, New Zealand, (Nalin.Pahalawaththa@transpower.co.nz, Mohamed.Zavahir@transpower.co.nz ). sentation. These models are used with power flow studies and for stability analysis at very low frequencies $(f<5 \mathrm{~Hz})$ only, whereas they show very poor performance with more detailed stability studies. The model presented in [2] uses a special form of discretisation, applying Poincare mapping, for the particular Kayenta TCSC installation. The model derivation for a different system will be similarly tedious and the final model form is not convenient for the application of standard stability studies and controller design theories. A similar final model form is derived in [3], however the model derivation is improved since direct discretisation of the linear system model is used. The importance of having a state-space represented, linear continuous system model, is well recognized in [4]. The model derivation in this case is based on a complex mathematical procedure encompassing averaging and integration, followed by discrete representation and the subsequent model conversion into linear continuous form. The model also does not have a modular form for subsystem representation, which would enable studies of internal system dynamics and subsystem interactions. The approach used in [5] recognizes the benefits of modular system representation, with $d-q$ transformation used for coupling with the external AC system. However, since the open loop approach is used, the model does not address issues of coupling with the static controller model and coupling with the Phase Locked Loop (PLL). The modeling principle reported in [6] employs rotating vectors that are difficult to use with stability studies, and only considers the open loop configuration. The SVC model developed in [7] is in a convenient final form, nevertheless it is oversimplified and the derivation procedure for non-linear segments is cumbersome. Most of the reported models are therefore concerned with a particular system, a specific operating problem or particular type of study and many do not include control elements.

An ideal SVC system dynamic model would possess, beside high accuracy, a convenient (linear state-space) model form, and it would adequately represent most practical parameters and variables. The model should be compatible with modern control theories and preferably be readily implemented with software tools like MATLAB.

This research adopts a systematic modeling approach by segmenting the system into three subsystems and individually modeling them with $d-q$ transformation and matrix coupling between them to achieve the above properties. It also seeks to offer complete closed loop model verification in the time and frequency domains. The modeling method resembles the one used with HVDC-HVAC systems in [8] and [9]. 


\section{TEST SYSTEM}

The test system in use consists of a SVC connected to an $\mathrm{AC}$ system that is represented by an equivalent impedance and a local load, as shown in Figure 1. The SVC is very similar to the one proposed in [10] and used as tutorial example in [11], except that non-linear transformer effects (saturation and magnetizing current) are neglected. The AC system model is also based on [11], with the introduction of an additional local load and a variation in system impedance to represent different and extreme system strengths. Two AC system configurations are considered: System 1 with equivalent impedance $\mathrm{z}_{1}=72 \Omega \angle 54^{\circ}$ (200MVA), and System 2 having ten times increased strength $\mathrm{z}_{2}=7.2 \Omega \angle 85^{\circ}$ (2000MVA) in order to fully validate the model accuracy and flexibility.

The control system is structurally based on [11] but gains are adjusted to reflect changes in the AC system. The test system data are given in the Appendix.

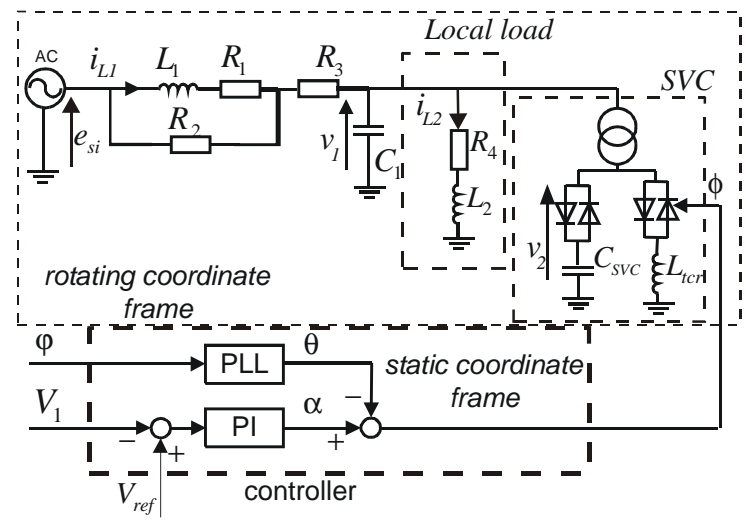

$$
\begin{aligned}
& \alpha \text { - Calculated firing angle } \\
& \theta \text { - PLL reference angle } \\
& \phi \quad \text { - Actual firing angle } \\
& V_{1}, \varphi \text { - Mag, phase angle of } v_{1} \\
& v_{1}=V_{1} \cos (\omega t+\varphi)
\end{aligned}
$$

PLL - Phase Locked Loop PI - Voltage PI controller TCR - Thyristor Controlled Reactor

Figure 1. Test system configuration.

\section{ANALYTICAL MODEL}

\section{A. Model structure}

To avoid pitfalls with modeling complex systems, the system model is here divided into three subsystems: an AC system model, a SVC model and a controller model. Each subsystem is developed as a standalone state-space model, linking with the remaining two subsystems and with the outside signals. With this structure, the subsystems can be analyzed independently and their influence after the model connections can be investigated, whilst enabling convenient coupling with more complex, future configurations.

The state-space model for a subsystem unit " $i$ " takes the following generic form:

$$
\begin{aligned}
& \underline{x}_{i}=A_{i} \underline{x}_{i}+\sum_{j} B_{i j} \underline{u}_{i j}+B_{i} \underline{u}_{\text {out }} \\
& \underline{y}_{i k}=C_{i k} \underline{x}_{i}+\sum_{j} D_{i j k} \underline{u}_{i j}+D_{\text {ioutk }} \underline{u}_{\text {out }} \\
& \underline{y}_{\text {iout }}=C_{\text {iout }} \underline{x}_{i}+\sum_{j} D_{i j o u t} \underline{u}_{i j}+D_{\text {ioutout }} \underline{u}_{\text {out }}
\end{aligned}
$$

where each of the indices $i, j$ and $k$, take all values from the set of three textual labels: " $a c$ " $-\mathrm{AC}$ system, " $c$ " -SVC, "co" Controller, where the following cases are excluded: $i=j$ and $i=k$. The variables with subscript "out" are the outside inputs and outputs. All matrices in the model (1) belong to the subsystem denoted by the first index " $i$ ". The input matrices, $B_{i j}$, take the second index " $j$ " from the particular input-side connecting subsystem (i.e.: $B_{\text {acco }}$ is the AC model input matrix that takes input signals from the controller), and the output matrices $C_{i k}$ have the second index " $k$ " associated with the linking subsystem that takes the particular output vector. With $D_{i j k}$ matrices the second and the third index label inputs and outputs, respectively.

\section{B. AC System Model}

The AC system model is linear, developed in the manner described in [8] and [9], and only a derivation summary is presented here.

A single-phase dynamic model is developed firstly, using the instantaneous circuit variables as the states. The test system uses a third order model with $i_{L 1}, i_{L 2}$ and $v_{1}$ as the states. A phase " $a$ " model is given below (to increase clarity of presentation we consider only one input link, one output link and only one $D$ matrix):

$$
\begin{aligned}
& \underline{x}_{a c a}=A_{a c a} \underline{x}_{a c a}+B_{a c a c o} \underline{u}_{\text {acaco }} \\
& \underline{y}_{\text {acaco }}=C_{\text {acaco }} \underline{x}_{a c a}+D_{\text {acacoco }} \underline{u}_{\text {acaco }}
\end{aligned}
$$

where the subscript "aca" denotes phase $a$ of the AC system. Using the single-phase model and assuming ideal system symmetry, a complete three-phase model in the rotating coordinate frame is readily created. To enable a wider frequency range dynamic analysis and coupling with the static coordinate frame, the above model is converted to the $d$ - $q$ static frame using Park's transformation [8],[12]. The AC model is represented in the $d$ - $q$ frame as:

$$
\begin{gathered}
\underline{x}_{a c}=A_{a c} \underline{x}_{a c}+B_{a c c o} \underline{u}_{a c c o} \\
\underline{y}_{a c c o}=C_{a c c o} \underline{x}_{a c c o}+D_{a c a c o c o} \underline{u}_{a c c o} \\
A_{a c}=\left[\begin{array}{cc}
A_{a c a} & -\omega_{o}[I]_{n x n} \\
\omega_{o}[I]_{n x n} & A_{a c a}
\end{array}\right], \quad B_{a c c o}=\left[\begin{array}{cc}
B_{a c a c o} & {[0]_{n x m}} \\
{[0]_{n x m}} & B_{a c a c o}
\end{array}\right], \\
C_{a c c o}=\left[\begin{array}{ll}
C_{a c a c o} & {[0]_{r x n}} \\
{[0]_{r x n}} & C_{a c a c o}
\end{array}\right], \quad D_{\text {accoco }}=\left[\begin{array}{cc}
D_{\text {acacoco }} & {[0]_{\text {rxm }}} \\
{[0]_{\text {rxm }}} & D_{\text {acacoco }}
\end{array}\right],
\end{gathered}
$$

where $\omega_{0}=2 \pi f, n$ - is the AC system order, $m$ - the number of inputs, and $r$ - the number of outputs. The states, inputs and outputs in the above model are the $d-q$ components of the instantaneous system variables:

$$
\underline{x}_{a c}=\left[\begin{array}{c}
x_{\text {acad }} \\
x_{\text {acaq }}
\end{array}\right], \underline{u}_{\text {acco }}=\left[\begin{array}{l}
u_{\text {acacod }} \\
u_{\text {acacoq }}
\end{array}\right], \underline{y}_{\text {acco }}=\left[\begin{array}{l}
y_{\text {acacod }} \\
y_{\text {acacoq }}
\end{array}\right]
$$

\section{Static VAR Compensator Model}

The static VAR compensator under consideration is a 
twelve pulse system with two six pulse groups in $\Delta$ connection and coupled with the network through a single, three-winding transformer with $\mathrm{Y}$ and $\Delta$ secondaries [10],[11].

The SVC impedances are converted to Y configuration and transferred to the primary transformer voltage. Each six-pulse group consists of the transformer model, the thyristor controlled reactor (TCR) and the capacitor unit in parallel with a resistance. An equivalent, six-pulse group model is shown in the singe phase diagram in Figure 2.

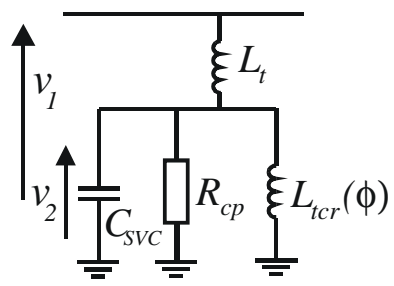

Figure 2. SVC electrical circuit model

The model can be represented in the state-space domain as follows:

$$
\begin{aligned}
\dot{i}_{t} & =\frac{1}{L_{t}} v_{1}-\frac{1}{L_{t}} v_{2} \\
\dot{v}_{2} & =\frac{1}{C_{s v c}} i_{t}-\frac{1}{C_{s v c}} i_{t c r} \\
i_{t c r} & =\frac{1}{L_{t c r}(\phi)} v_{2}
\end{aligned}
$$

Equation (8) is non-linear in view of the fact that the TCR reactance is dependent upon the firing angle obtained from the controller model. This equation cannot be directly linearised since the SVC model is developed in the AC frame with oscillating variables, (i.e. $v_{2}=V_{2} \cos (\omega t+\varphi)$ ) whereas the firing angle signal is derived as a signal in the controller reference frame (i.e. a non-oscillating signal).

To link the SVC model with the controller model, the approach of artificial rotating susceptance is adopted. It is firstly presumed that the AC terminal voltage has the following value in the steady state: $v_{2}^{o}=V_{2}^{o} \cos \left(\omega t+\varphi^{o}\right)$, where superscript "o" denotes the steady-state variable, i.e., $V_{2}{ }^{0}$ is a constant magnitude, $\varphi^{o}$ is a constant angle and $\nu_{2}^{o}$ is a rotating vector of a constant magnitude and angle. The susceptance value in the steady-state is $1 / L_{t c r}^{o}$.

Assuming small perturbations around the steady state we have:

$$
\begin{aligned}
& v_{2}=\left(v_{2}^{o}+\Delta v_{2}\right) \\
& 1 / L_{t c r}=1 / L_{t c r}^{0}+\Delta\left(1 / L_{t c r}\right) .
\end{aligned}
$$

Small perturbations are justified assuming an effective voltage control at the nominal value. Multiplying the terms in (9) and (10) and substituting in (8) results in:

$$
\Delta \dot{i}_{t c r}=v_{2}^{o} \Delta\left(1 / L_{t c r}\right)+\Delta v_{2} / L_{t c r}^{o}+\Delta v_{2} \Delta\left(1 / L_{t c r}\right)
$$

The susceptance in (11) is further represented, using only the fundamental component, as [13]:

$$
L_{t c r}=\frac{L_{t c r m} \pi}{(2 \pi-\phi)-\sin (2 \pi-\phi)},
$$

where $L_{\text {tcrm }}$ corresponds to the maximum conduction period, $\phi=90^{\circ}$. Equation (12) can be linearised as:

$$
\Delta\left(1 / L_{t c r}\right)=K_{s v c} \Delta \phi, K_{s v c}=\partial\left(1 / L_{t c r}\right) / \partial \phi .
$$

The above linearisation is justified in practice since most modern SVC control systems will have a gain compensation scheme (look-up table) that maintains a constant system gain [13].

In view of (13), and neglecting the small terms, equation (11) is written as:

$$
\Delta \dot{i}_{t c r}=v_{2}^{o} K_{s v c} \Delta \phi+\Delta v / L_{t c r}^{o}
$$

and it replaces (8) in the model. Equation (14) is in the AC coordinate frame, and the following term:

$$
v_{2}^{o} K_{s v c} \Delta \phi=V_{2}^{o} K_{s v c} \Delta \phi \cos \left(\omega t+\varphi^{o}\right)
$$

is an artificial oscillating variable (susceptance) that has a varying magnitude and a constant angle equal to the voltage nominal angle. In this way, the SVC model (6),(7),(14) has all oscillating variables that are converted to $d$ - $q$ variables, as is done with the AC system model in (3)-(5). Subsequently, using the $d-q$ components of the inputs and outputs, this model is linked with the other model units. In order to link the $d-q$ components of the rotating susceptance (15) with the controller module, these components are further converted to magnitudeangle components using the $x-y$ to polar co-ordinate transformation [8].

It should be noted that the transformer impedance $\left(L_{t}\right)$ must be included in this model since the eigenvalue analysis proves that this parameter has noticeable effects on system dynamics. This conclusion is contrary to HVDC modeling principles, since it has been demonstrated [8],[9] that transformer dynamics can be excluded from system dynamic models.

\section{Controller Model}

The controller model consists of a second order feedback filter, PI controller, Phase Locked Loop (PLL) model and transport delay model, as shown in Figure 3. The PLL system is of the $d-q-z$ type and its functional diagram is given in [14] and [10], whereas the state space linearised second-order model is developed in [8].

The delay filter does not have dynamic equivalent in the actual system. It is introduced to represent the effects of the discrete nature of the signal transfer caused by thyristor firings at discrete instants in the fundamental cycle. This simplified continuous-element modeling of a discrete phenomenon has limited accuracy, but the model application value is much increased with the continuous form and, as demonstrated in the following sections, accuracy proves satisfactory for most applications. Researchers in [1] conclude that the delay filter time constant has a value of 3-6ms and reference [13] suggests $2.77 \mathrm{~ms}$. During the proposed model verification, simulation studies have suggested that the value of approximately $T_{d}=2.85 \mathrm{~ms}$ is used, which is in agreement with the above rec- 
ommendations.

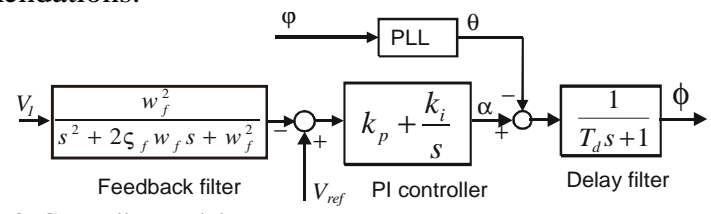

Figure 3. Controller model

\section{E. Model Connections}

The above three models are linked to form a single system model in the state-space form. The final model has the following structure:

$$
\begin{aligned}
& \underline{x}_{s}=A_{s} \underline{x}_{s}+B_{s} \underline{u}_{\text {out }} \\
& \underline{y}_{\text {out }}=C_{s} \underline{x}_{s}+D_{s} \underline{u}_{\text {out }}
\end{aligned}
$$

where " $s$ " labels the overall system and the model matrices are:

$$
\begin{aligned}
A_{s} & =\left[\begin{array}{ccc}
A_{c o} & B_{c o t} * C_{t c c o} & B_{c o a c} * C_{a c c o} \\
B_{t c c o} * C_{c o t} & A_{t c} & B_{t c a c} * C_{a c t c} \\
B_{\text {acco }} * C_{c o a c} & B_{a c t c} * C_{t c a c} & A_{a c}
\end{array}\right] \quad(17) \\
B_{s} & =\left[\begin{array}{l}
B_{\text {coout }} \\
B_{\text {tcout }} \\
B_{\text {acout }}
\end{array}\right], C_{s}=\left[\begin{array}{lll}
C_{\text {coout }} & C_{\text {tcout }} & C_{\text {acout }}
\end{array}\right], D_{s}=[0]
\end{aligned}
$$

All the subsystems' D matrices are assumed zero in (17) since they are zero in the actual model and this noticeably simplifies development.

The matrix $A_{s}$ has the subsystem matrices on the main diagonal, with the other sub-matrices representing interactions between subsystems. The model in this form has advantages in flexibility since, as an example, if the SVC is connected to a more complex AC system only the $A_{a c}$ matrix and the corresponding input and output matrices need modifications. Different FACTS can be modeled using the TCR/SVC model unit or, similarly, more advanced controllers can be developed using modern control theory $\left(\mathrm{H}_{\infty}, \mathrm{MPC}, ..\right)$ and implemented directly by replacing the $A_{c o}$ matrix. The above structure enables the model to be readily interfaced with the MATLAB HVDC model or other FACTS elements or Power Systems Blockset, for the purpose of investigating interactions and coordination.

\section{MODEL VERIFICATION}

\section{A. Time domain}

The model was implemented in MATLAB and tested against the detailed, non-linear simulation PSCAD/EMTDC. In the time domain, step responses were verified using the controller reference as the input, given by $V_{\text {ref }}$ in Figure 3, and the disturbance represented by the $e_{s i}$ magnitude variation in Figure 1.

Figures 4 and 5 show the System 1 verification for the reference and disturbance inputs, respectively. Very good response matching is evident for the voltage magnitude output signal; similar matching was confirmed for all other model variables that are not shown. To confirm the model robustness with dif- ferent system parameters, System 2 was also tested and the results are shown in Figures 6 and 7. A satisfactory response matching is clear and the accuracy is further emphasized, since the lightly damped oscillatory mode at $70 \mathrm{~Hz}$ in the case of the disturbance input (Figure 7) is very well represented. As seen in Figure 7, however, MATLAB gives more noticeable error in the phase angle, particularly at high frequencies.

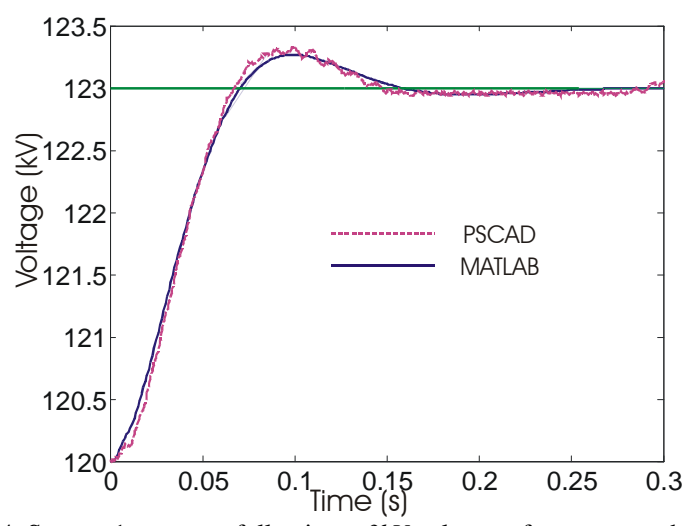

Figure 4. System 1 response following a $3 k V$ voltage reference step change.

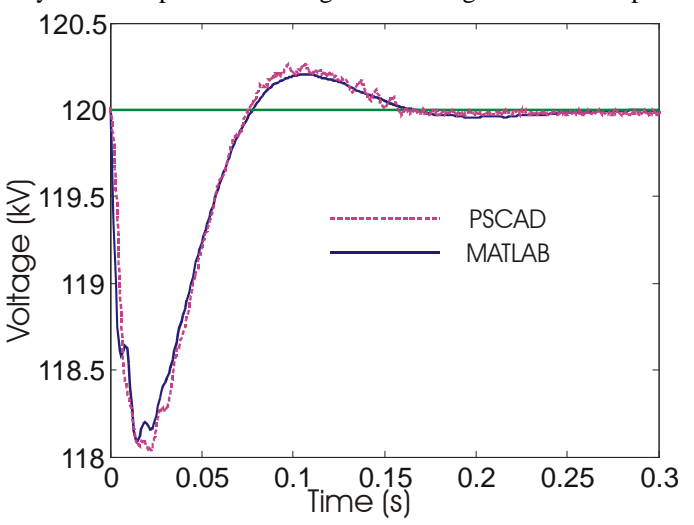

Figure 5. System 1 response following a $2 k V$ disturbance (remote source) step change.

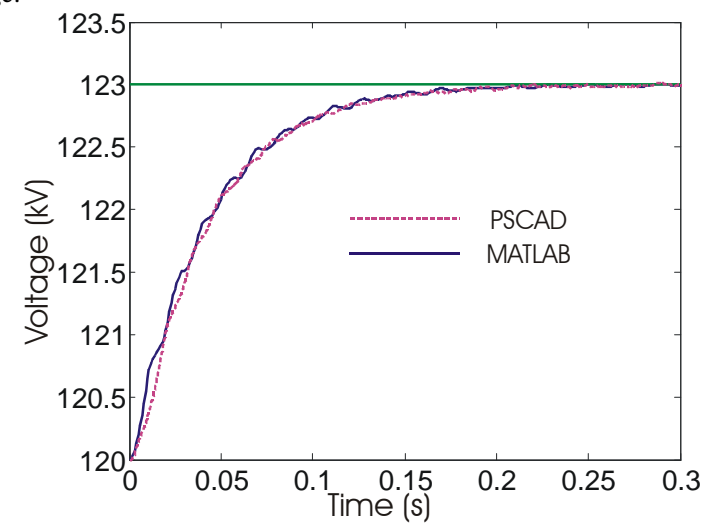

Figure 6. System 2 response following a $3 k V$ voltage reference step change.

\section{B. Frequency domain}

The two test systems were also tested against PSCAD in the frequency domain. PSCAD does not possess a frequency domain analysis capability, and the results were obtained "manually", by injecting a single frequency component at a time. The individual points were then linked in a single curve with minimal filtering of the experimental data. 


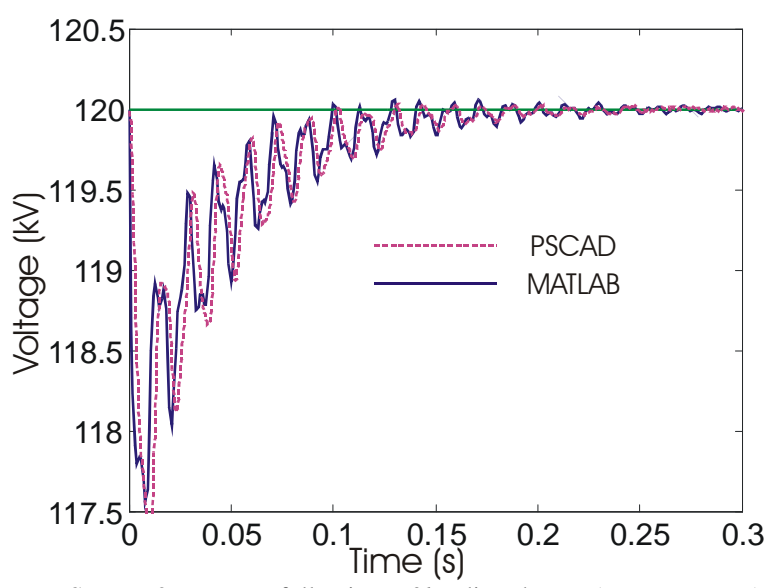

Figure 7. System 2 response following a $2 k V$ disturbance (remote source) step change.

Figure 8 shows the gain frequency response comparison in the frequency range $1-150 \mathrm{~Hz}$, where the "error" is the difference between the two curves. Very good matching was found across the entire frequency range, and at higher frequencies the error is mostly within a $5 \mathrm{~dB}$ envelope. Certainly, below $40 \mathrm{~Hz}$ very high accuracy is evident.

The phase angle frequency response is shown in Figure 9. In this case the error increased, and particularly in the frequency range $25-60 \mathrm{~Hz}$ was pronounced. This result is a consequence of poor representation of the discrete system: if the delay filter in the controller model is omitted the error increases. Research is currently under way to offer new modeling approaches to eliminate this phase error.

In the majority of applications at higher frequencies, such as the analysis of amplification of a particular oscillatory mode in the system, the system gain is of primary importance, and in this aspect the model represents the system correctly in a wide frequency range.

Regarding the overall time and frequency domain responses, and being aware of the phase response errors, it can be concluded that the model has reasonably good accuracy when employed as a design and analysis tool for phenomena such as subsynchronous resonance, or interactions with other fast FACTS/HVDC controls.

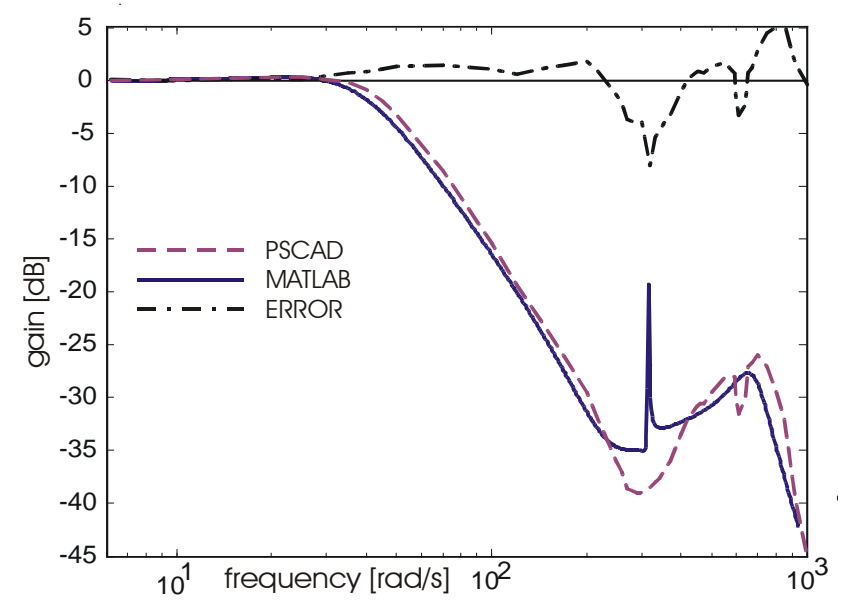

Figure 8. System 1 gain frequency response with the reference voltage input.

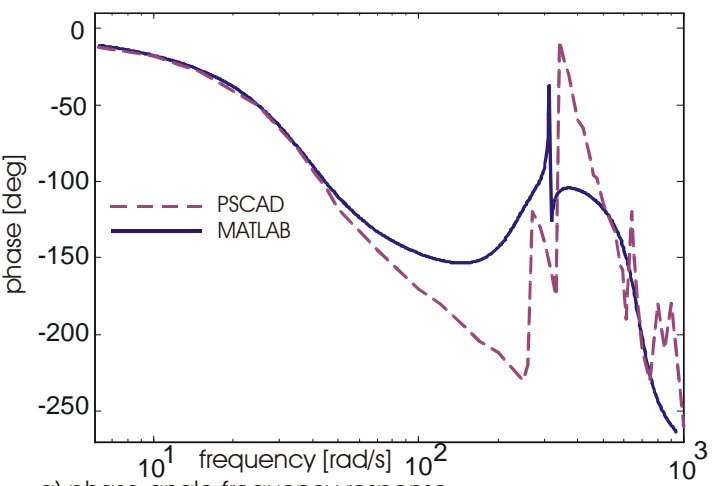

a) phase angle frequency response

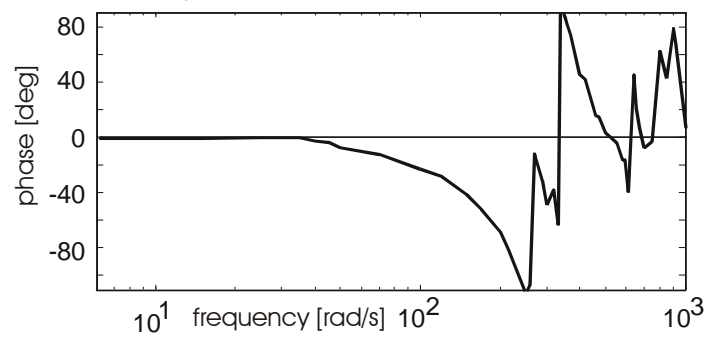

b) error (PSCAD-MATLAB) in phase angle frequency response

Figure 9. System 1 phase frequency response with the reference voltage input.

\section{STUDY OF INFLUENCE OF PLL GAINS}

This section gives an example of the model use in the system dynamic analysis. A PLL is typically used with thyristor converters to provide the reference signal that follows the synchronizing line voltage or current. As a dynamic element, a PLL will also have influence on the system's dynamic responses and stability, although this aspect not been analyzed in the FACTS/HVDC references. Further, since a PLL has two adjustable gains $\left(k_{p}\right.$ and $\left.k_{I}\right)$, these can be used as a convenient means of adjusting system performance in respect of stability issues or improving performance.

Figure 10 shows the dislocation of dominant eigenvalues after reduction in the PLL gains. As the gains are reduced, the eigenvalues migrate from the original " $\mathrm{x}$ " to the location "o", representing ten times reduced gains. It is seen that the PLL gains have significant influence on the system dynamics and that the frequency of the dominant oscillatory mode reduces, accompanied by a small reduction in mode damping (branch " $a$ "). The next dominant real mode is at the same time moved away from the imaginary axis, as shown by the branch " $b$ ".

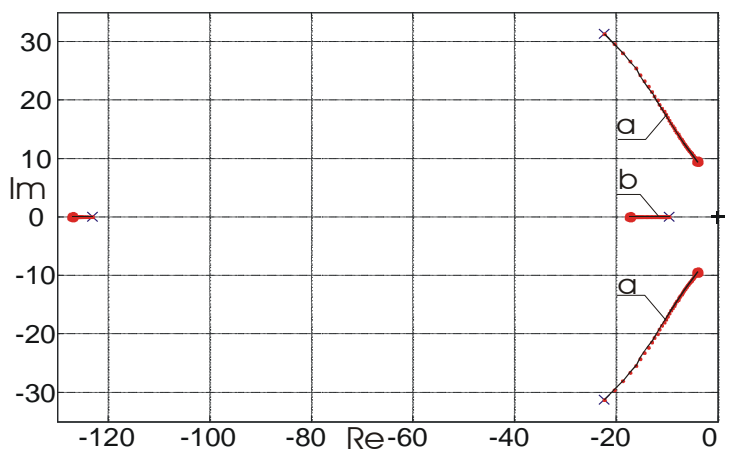

Figure 10. System 1. Influence of the PLL gains on the system eigenvalue location. "x" - original eigenvalues, "o" - final location with 10 times reduced gains. 


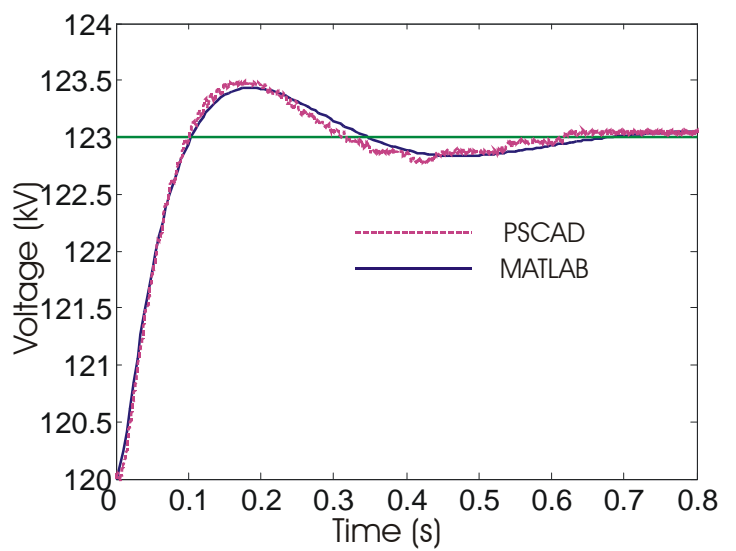

Figure 11. System 1 with PLL gains reduced ten times. System response following a $3 \mathrm{kV}$ voltage reference change.

This result was confirmed with PSCAD simulation, as shown in Figure 11. Although not shown in Figure 10, the increase in the PLL gains increases the speed of response and it is suggested that this effect on the positioning of the dominant mode can be exploited in the design stage to improve performance, or to avoid negative interactions at a particular frequency.

\section{CONCLUSIONS}

This paper presents a state-space linear continuous model of a Static VAR Compensator. The model is built of three individual subsystem models: an AC system, a SVC and a controller model. Such a structure enables model application to a wide range of system configurations. The issue of the nonlinear susceptance-voltage relationship and coupling with the rotating coordinate frame is solved using an artificial rotating susceptance that has a variable magnitude. The representation of a discrete system using a first order filter proved adequately accurate. Model verification in the time and frequency domains against a PSCAD simulation confirmed very high accuracy for $f<25 \mathrm{~Hz}$, and fair accuracy even beyond the first harmonic frequencies. The phase angle frequency response shows less precise matching, particularly in a certain mid-frequency band. The model's application to the analysis of dynamic influence of PLL gains variation is demonstrated. The eigenvalue dislocation reveals, confirmed with digital simulation, that a reduction in PLL gains has a negative influence on system stability.

\section{APPENDIX}

TABLE I.

TEST SYSTEM DATA

\begin{tabular}{|l|l|l|}
\hline \multicolumn{4}{|l|}{ AC system data: } \\
\hline \multicolumn{1}{|l|}{} & System 1 & System 2 \\
\hline$R_{1}$ & $0.6 \Omega$ & $0.3 \Omega$ \\
\hline$R_{2}$ & $200 \Omega$ & $2000 \Omega$ \\
\hline$R_{3}$ & $0.1 \Omega$ & $0.1 \Omega$ \\
\hline$R_{4}$ & $300 \Omega$ & $300 \Omega$ \\
\hline$L_{1}$ & $0.3 \mathrm{H}$ & $0.023 \mathrm{H}$ \\
\hline$L_{2}$ & $0.2 \mathrm{H}$ & $0.2 \mathrm{H}$ \\
\hline$Z(M V A)$ & $72 \Omega \angle 54^{\circ}(200 \mathrm{MVA})$ & $7.2 \Omega \angle 85^{\circ}(2000 \mathrm{MVA})$ \\
\hline$V_{1}$ & $120 \mathrm{kV}$ & $120 \mathrm{kV}$ \\
\hline Controller data & $4 \mathrm{e}-3 \mathrm{rad} / \mathrm{kV}$ \\
\hline$k_{p}$ & $8.33 \mathrm{e}-4 \mathrm{rad} / \mathrm{kV}$ & \\
\hline
\end{tabular}

\begin{tabular}{|l|l|l|}
\hline$K_{I}$ & $0.417 \mathrm{rad} /(\mathrm{kVs})$ & $2.5 \mathrm{rad} /(\mathrm{kVs})$ \\
\hline$T_{d}$ & $2.85 \mathrm{e}-3 \mathrm{~s}$ & $2.85 \mathrm{e}-3 \mathrm{~s}$ \\
\hline$\zeta_{f}$ & 0.5 & 0.5 \\
\hline$\omega_{f}$ & $753.6 \mathrm{rad} / \mathrm{s}$ & $753.6 \mathrm{rad} / \mathrm{s}$ \\
\hline$P L L k_{p}$ & 100 & 100 \\
\hline$P L L k_{I}$ & $9001 / \mathrm{s}$ & $9001 / \mathrm{s}$ \\
\hline SVC data $(+167 /-100 \mathrm{MVA})$ \\
\hline Total reactive MVA & $100 \mathrm{MVA}$ \\
\hline Total capacitive MVA & $167 \mathrm{MVA}$ \\
\hline Transformer voltages & $120 \mathrm{kV} / 12.65 \mathrm{kV}$ \\
\hline Transformer rating MVA & $200 \mathrm{MVA}$ \\
\hline Transformer Xps, Xpd, Xsd & $0.17 \mathrm{pu}, 0.17 \mathrm{pu}, 0.021 \mathrm{pu}$ \\
\hline Resistance $\mathrm{R}_{\mathrm{cp}}$ & $167 \Omega$ \\
\hline
\end{tabular}

\section{REFERENCES}

[1] IEEE Special Stability Controls Working Group "Static Var Compensators models for Power Flow and Dynamic Performance Simulation" IEEE Trans. on Power Systems, V9, No 1, pp 229-240, February 1994.

[2] S.J.Jalali, R.H.Lasseter I.Dobson, "Dynamic Response of a Thyristor Controlled Switched capacitor" IEEE Trans. On Power Delivery, Vol 9, No 3, July 1994. Pp 1609-1615.

[3] A. Ghosh, G.Ledwich, "Modelling and control of thyristor controlled series compensators" IEE Proc. Generation Transmission and Distribution, Vol. 142, No 3, May 1995. Pp 297-304.

[4] H. A. Othman, L Angquist, "Analytical Modelling of Thyristor-Controlled Series capacitors for SSR Studies", IEEE Transactions on Power Systems, Vol. 11, No 1, February 1996. Pp 119-127.

[5] B.K.Perkins, "Dynamic modelling of a TCSC with Application to SSR Analysis" IEEE Transactions on Power Systems, Vol 12, No 4, November 1997, Pp. 1619-1625.

[6] Mattavelli P, Verghese GC, Stankovic AM, "Phasor Dynamics of Thyristor Controlled Series Capacitor Systems" IEEE Transactions on Power Systems, Vol.12, No.3, Aug. 1997, Pp.1259-67.

[7] Davies M. "Control Systems for Static Var Compensators", Ph.D. Thesis, 1997, Staffordshire University.

[8] D.Jovcic "Control of High Voltage DC and Flexible AC Transmission Systems", Ph.D. Thesis, University of Auckland, Auckland, New Zealand, 1999.

[9] D.Jovcic N.Pahalawaththa, M.Zavahir "Analytical Modelling of HVDC Systems” IEEE Trans. on PD, Vol. 14, No 2, April 1999, Pp. 506-511.

[10] A.M.Gole, V.K.Sood, "A Static Compensator Model for use with Electromagnetic Transients Simulation Programs” IEEE Transactions on Power Delivery, Vol 5, No 3, July 1990, Pp. 1398-07.

[11] Manitoba HVDC Research Center "PSCAD/EMTDC Users manual" Tutorial manual, 1994.

[12] Kundur,P "Power System Stability and Control", McGraw Hill, Inc. 1994.

[13] N.Hingorani, Laszlo Gyugyi, "Understanding FACTS", IEEE Press 2000.

[14] A. Gole, V.K. Sood, L. Mootoosamy, "Validation and Analysis of a Grid Control System Using D-Q-Z Transformation for Static compensator Systems", Canadian Conference on Electrical and Computer Engineering Montreal, PQ, Canada September 1989, Pp.745-748.

\section{BIOGRAPHIES}

Dragan Jovcic (S'97, M'00) obtained a B.Sc. (Eng) degree from the University of Belgrade, Yugoslavia in 1993 and a Ph.D. degree from the University of Auckland, New Zealand in 1999. He worked as a design Engineer in the New Zealand power industry from 1999-2000. Since April 2000 he has been employed as a Lecturer with the University of Ulster, UK. His research interests lie in the areas of control systems, HVDC systems and FACTS.

Nalin Pahalawaththa obtained the degrees, B.Sc (Eng) from University of Moratuwa, Sri Lanka in 1981 and PhD from University of Calgary, Canada in 1988. He worked as a post doctoral fellow at University of Canterbury, New Zealand during the period 1988-1990 and then joined the University of Auckland, New Zealand where he was a Professor. Since 2000 he has been with Transpower NZ Ltd as a system architect. His research interests are power system analysis and control. 
Mohamed Zavahir obtained the degrees, B.Sc (Eng) from University of Peradeniya, Sri Lanka in 1987 and PhD from University of Canterbury, New Zealand in 1992. He worked as a post doctoral fellow at University of Canterbury, New Zealand during 1992-1993 and then joined Trans Power New Zealand Limited where he is currently employed as a Senior Network Support engineer. His research interests are power system transients, insulation coordination and HVDC transmission.

Heba A. Hassan obtained the first class honours (distinction) degree in Electrical Engineering from Cairo University in 1995. From 1995 to 1998, she worked as a teaching and research assistant at Cairo University. Her MSc degree (1999) in Electrical Engineering is from Cairo University. From 1998 to 1999, she was an Academic Visitor at the Department of Electrical and Electronic Engineering, Imperial College, London. Currently, she is fulfilling her $\mathrm{PhD}$ degree at the University of Ulster, UK. Her research interests include power system stability and control, FACTS modelling, and robust adaptive control. 